\title{
Ler e compartilhar sentidos para formar estudantes-leitores
}

\section{Reading and sharing senses to form student-readers}

\author{
Marcela Afonso Fernandez, Bianca Dias de Souza \\ Universidade Federal do Estado do Rio de Janeiro (UNIRIO), Brasil,
}

\begin{abstract}
Resumo
Esta comunicação se propõe a compartilhar os achados e reflexões mais significativos obtidos tomando por base a pesquisa de extensão Ler e Compartilhar: práticas de formação solidária, articulada a pesquisa acadêmica Contações de histórias, rodas e encontros com a leitura literária: das tradições à virtualidade. $\mathrm{O}$ principal objetivo que as norteia é investigar alguns modos de ser leitor e tecer a leitura produzindo sentidos, realizados por um grupo de estudantes da Universidade Federal do Estado do Rio de Janeiro (UNIRIO), em especial, os oriundos do Curso de Licenciatura em Pedagogia, por meio da estratégia círculo de leitura.

Palavras-chave: formação de estudantes-leitores, círculos de leitura, literatura.
\end{abstract}

\begin{abstract}
This paper intends to share the findings and most significant observations collected according to the extension research named Reading and Sharing: practices of supportive degree, related to the academic research Storytelling, groups and meetings with literature: from tradition to virtual. The main goal surrounding it is to investigate some ways of being a reader and weave the reading producing senses, performed by a group of students from Federal University of Rio de Janeiro (UNIRIO), specially, those originated from the Graduate School of Pedagogy, by means of the reading circle strategy.

Keywords: formation of student-readers, reading circles, literature.
\end{abstract}

\section{Leituras tecidas em círculo}

Neste trabalho, temos o objetivo de apresentar uma das possibilidades de formação de estudantes-leitores, considerando um olhar emancipatório de apropriação do texto literário. Para tanto, nos pautamos na experiência do círculo de leitura literária, realizada no projeto de extensão Ler e Compartilhar: práticas de formação solidária, que é vinculada a uma das linhas investigativas da pesquisa Contações de histórias, rodas e encontros com a leitura literária: das tradições à virtualidade, e que deu origem ao trabalho monográfico $O$ papel da leitura literária na formação do estudante de Pedagogia, desenvolvido por Bianca Dias de Souza. Nessas investigações, focalizamos os processos de formação de leitores na Universidade Federal do Estado do Rio de Janeiro (UNIRIO), tendo como público-alvo estudantes dos Cursos de Licenciatura, em especial, os oriundos da Licenciatura em Pedagogia.
$\mathrm{O}$ círculo de leitura literária, prática solidária e generosa, se propõe a acolher pessoas com histórias de vida distintas. Essa prática é desenvolvida em encontros informais por um mediador, o leitor-guia, que a partir da leitura oral do texto literário estimula a criação de teias interpretativas e diálogos espontâneos entre os leitores participantes. Nessa prática, o tempo de realização é variável e o local tende a ser acolhedor, pois todos os participantes ficam sentados em roda. Desta forma, ninguém prevalece sobre os demais.

Diferentes estudos teóricos e investigações atestam que nem sempre os estudantes possuem contato com a literatura em sua vida cotidiana, o que dificulta demasiadamente a experiência de leitura e construção de sentidos nos contextos educativos formais. Nesta perspectiva, Lajolo (2000) aponta para a urgência da melhoria na qualidade da formação docente e na importância do trabalho de mediação que precisa realizar com a leitura literária. De acordo com Leite e Oliveira (2004, p. 30), “[...] é na interação social que o sujeito leitor se constitui. Nessa interação, ao observar e recriar, ele vai, aos poucos, desenvolvendo suas possibilidades."

O principal objetivo dos círculos de leitura do projeto de extensão Ler e Compartilhar: práticas de formação solidária é desenvolver com os estudantes das licenciaturas da UNIRIO práticas de leitura oral de textos literários (contos, crônicas, poesias, romances), que estimulem a imaginação, a ampliação dos sentidos e a construção de repertórios, com vistas a identificar alguns modos de ser leitor e tecer a leitura.

No círculo do Ler e Compartilhar, o texto literário estimula o diálogo, num percurso de cooperação e troca de experiências para a produção de sentidos. Interpretações, devaneios e sensações evocam as memórias de leitura e o repertório de narrativas de todos que partilham dessa experiência solidária e crítica. O que distingue essa experiência de outras práticas de leitura é a oportunidade de, a partir da disposição dos participantes em círculo, podermos a cada encontro corporificar a troca espontânea, divergente ou complementar das vivências e escutas de cada leitor envolvido com o texto literário.

Os círculos de leitura ocorrem uma vez a cada semana na Biblioteca da UNIRIO, ambiente gerador de leitura propício para adentrarmos no universo da literatura. Além de desenvolver a leitura compartilhada nesses encontros semanais, o projeto Ler e Compartilhar possui 
uma página virtual no Facebook, Ler e compartilhar práticas de formação solidária, na qual são postadas trechos e obras de escritores diversos, bem como dicas, notícias e eventos que envolvam o universo da literatura.

Cada leitor participante dos círculos do Ler $e$ Compartilhar pode tornar-se leitor-guia, a partir do seu interesse, assumindo o papel de mediador responsável por selecionar e realizar as leituras tecidas de forma colaborativa e interativa pelo grupo.

Normalmente, os gêneros literários, temas e escritores selecionados advêm do interesse e da motivação dos leitores participantes, que são livremente expressos a cada encontro. Concomitantemente, em sintonia com um dos objetivos da pesquisa Contações de histórias, rodas e encontros com a leitura literária: das tradições à virtualidade, que se propõe a oportunizar ao leitor literário o acesso a gêneros e temas que diversifiquem a sua visão acerca de nossas matrizes culturais, temos valorizado e incluído nos círculos do Ler e Compartilhar textos provenientes da literatura de matriz africana e afro-brasileira (Parreiras; Machado, 2012).

Com isso, a partir da expressão artística e da diversidade cultural contida na literatura, intentamos ampliar em nossos leitores o conhecimento sobre nossas matrizes africanas, assegurando o valor dessas culturas em relação à matriz européia, bem como respondendo as demandas por uma sociedade mais democrática, explicitada pela promulgação da Lei 10.639/2003, que estabelece diretrizes curriculares para a educação das relações étnico-raciais e para o ensino de História e Cultura Afro-brasileira e Africana, constituindo uma resposta às demandas pelo reconhecimento, valorização e afirmação de direitos da população negra no Brasil.

Ao incluirmos nos círculos do Ler e Compartilhar obras escritas por escritores de origem africana e afro-brasileira que revelem a multiculturalidade, as etnias, as tradições e as artes advindas desses povos, enfatizamos, sobretudo a necessidade de "consciência política e histórica da diversidade, o fortalecimento das identidades e de direitos e ações educativas de combate ao racismo e as discriminações" (Souza, 2009, p.79).

Destacamos a seguir alguns achados sobre as experiências de três leitores-participantes obtidos a partir da realização do círculo de leitura Ler e Compartilhar, com base na entrevista desenvolvida no trabalho monográfico O papel da leitura literária na formação do estudante de Pedagogia. Nosso objetivo principal nessa etapa da investigação foi verificar como esses sujeitos se sentiram como leitores ao compartilharem as leituras em grupo.

\section{Como você se vê como leitor participante do Ler e Compartilhar?}

Leitor 1: Como participante desta atividade tão prazerosa, afirmo que aprendi muito com todos que fazem parte do grupo, docente e discentes. A variedade de contos, histórias são importantes para levar o leitor a pensar, a penetrar no contexto e a ler as entrelinhas. Algumas tão envolventes que ficam gravadas e oferecem possibilidades de conhecer diversas culturas onde a imaginação que é ilimitada viaja e nos leva por caminhos estreitos e largos, mas que através da leitura podemos ampliar, encontrar saidas, nos encontrar, nos reconhecer e nos identificar. A leitura tem essa magia de ativar os sentidos e até os cheiros, de motivar, de rir e até de sonhar.

Tudo isto é reflexo de Ler e Compartilhar, não só comigo mesmo, mas ao recordar uma passagem de um texto, me colocar naquele lugar ou levar o outro a refletir e sobre as viagens que a vida nos leva, mesmo quando não planejamos. Algumas com final feliz e outras nem tanto, mas que podemos extrair sempre algo de bom para a vida. "O saber vincula, irmana, une" -Logosofia

Leitora 2: A minha experiência como leitora neste processo do Ler e do Compartilhar foi deveras enriquecedor. Foi através desses encontros que tive a oportunidade de conhecer outros tipos de produção textual e ir ao encontro cultural e social revelados pela literatura e pelos autores africanos. Ambos para mim desconhecidos totalmente.

$\dot{E}$ interessante ressaltar que a difusão dos conhecimentos, dos sentimentos e das interpretações que surgem a partir destas rodas de conversas, nos desinibem e, então, nos deixamos afetar pelo outro, seja ele, o leitor ou o autor. Sabemos que, neste jogo de revelações, é também possível afetarmos o outro. Quando desvendamos, eu e, ou, o(s) outro(s), aquilo que está entre o sujeito e as entrelinhas do escrito, o ouvir toma outra dimensão. Talvez, uma leitura sem esta dinâmica não se descobre o que está encoberto... Para a nossa formação, humana, profissional, como futuros professores ou não, esta interação só comprova o muito que com as trocas todos nós aprendemos.

Leitora 3: Participava no Ler e Compartilhar com muito entusiasmo, pois era um momento de "refrigério" em meio a tantas ocupações com os textos acadêmicos. No momento do círculo de leitura me sentia acolhida e a cada texto compartilhado podia experimentar a essência das palavras. Me conduzindo a melhorar meu olhar, minhas relações com os outros, aprendi a melhor selecionar os livros, aprimorar a escuta sensivel! Muitas vezes falamos muito e ouvimos pouco, mas escutar é estar sensível aquilo está sendo dito e lido.

É possível observar nas narrativas dos sujeitos citados anteriormente o prazer que a prática do círculo literário trouxe para cada um deles, como também as situações de aprendizagem que surgiram mediante as trocas com o grupo, como, por exemplo, o despertar da escuta sensível. Além disso, essa prática tornou-se uma válvula de escape e um local de acolhimento em meio a tantas ocupações com textos acadêmicos, que segundo a Leitora 3 "era um momento de refrigério".

As leituras literárias propiciadas pelo projeto Ler $e$ Compartilhar favorecem o encontro do leitor-participante consigo mesmo e com o outro, estabelecendo relações de identidade a partir do (re)conhecimento e interação com diferentes culturas, tempos, realidades sociais, etc. Apuram, também, o senso crítico, a imaginação e o desejo de ler, práticas que 
por vezes não ocorrem ou se perdem pela falta de estímulos e oportunidades nos espaços formativos.

Entendendo que os contextos educativos são fundamentais na constituição da cidadania político-social, que nem todos os indivíduos reconhecem as implicações de seus direitos e deveres, limites e possibilidades, ressaltamos a importância da democracia vivenciada na promoção desta experiência de leitura literária, em prol do diálogo e da participação cidadã.

Ademais, destacamos a presença de outras matrizes culturais, a saber, a africana, que no decorrer de muitos anos esteve ausente da literatura e, quando incluída, era relacionada apenas a figura do negro como um escravo (Ortiz, 1994). Partindo desta contatação, acreditamos que é possível colaborar para a promoção de uma sociedade mais justa e efetivamente valorizada por sua característica multicultural e multiétnica.

\section{A metodologia do Ler e Compartilhar em ação}

Utilizamos como desenho metodológico investigações de caráter qualitativo, tendo como principal instrumento de coleta de dados entrevistas semiestruturadas sobre a experiência dos leitores-participantes no círculo do Ler e Compartilhar. Por meio da estratégia círculo de leitura literária foi produzido um corpo de conhecimentos acerca das diversas concepções e práticas de leitura desses sujeitos.

O público-alvo é constituído por estudantes, a comunidade acadêmica da UNIRIO e o público em geral que frequenta a universidade (escritores, contadores de histórias, pesquisadores e leitores interessados pela literatura). Sendo assim, o perfil dos leitores é sempre renovado por novos participantes, mudando em cada encontro, o que torna plural e enriquecedora a experiência de leitura e construção de sentidos. Semanalmente, ao promovermos encontros com a duração de duas horas, recebemos novos leitores, dentre eles, estudantes de Biblioteconomia, Informática, Letras, Pedagogia e Teatro.

Apresentamos anteriormente alguns resultados obtidos decorrentes dessa experiência, relacionando o referencial teórico que fundamentou a pesquisa articulado com as transcrições na íntegra das entrevistas realizadas com três estudantes-leitores oriundos do curso de Pedagogia.

Nas investigações, em andamento, observamos que a forma pela qual o estudante de Pedagogia compreende o processo de leitura tende a fundamentar e orientar as rotinas e encaminhamentos que ele opta por realizar quando se vê diante da tarefa de dinamizar e acompanhar como professor a leitura nos ambientes educativos em que atua.

Ademais, as análises das entrevistas desenvolvidas com os estudantes ampliaram a compreensão sobre os diversos caminhos de formação de sujeitos-leitores, bem como o efeito dessas experiências nas maneiras como estes interpretam, concebem e interagem nos contextos locais onde transitam.

\section{Considerações Finais}

Ao enveredarmos pelo caminho da leitura literária situamos as palavras, o dito em outro patamar - o para além. Percebemos as nuances e as possibilidades imagéticas para além e com as palavras que, por vezes, fogem de nossas mentes racionais, mas que estão presentes em nossas mãos, escorrem por elas e dão um outro sentido ao texto e ao mundo.

Quando apresentamos ao estudante, futuro professor, situações em que ele seja provocado a se posicionar como leitor de obras literárias, como ocorre nos círculos do Ler e Compartilhar pretendemos evidenciar o compromisso envolvido quando atuamos na formação de leitores como mediadores de leitura perante diferentes textualidades. É a partir de experiências como as que vivemos que podemos nos abrir ou não para o universo da Literatura.

As entrevistas realizadas com os estudantes-leitores do Ler e Compartilhar ratificam a visão de que a prática do círculo de leitura atenua o desconforto gerado pelo contato com a obra literária, estimulando a formação do ser leitor e a interação com olhares a partir do encontro com diferentes percepções, sentidos, emoções, tempos e espaços. Por conseguinte, todos saem enriquecidos, uma vez que "[...] é na interação que o leitor é formado - no caso, interação com o professor, com os outros alunos e com os textos lidos" (Leite; Oliveira, 2004, p. 25).

Reconhecendo a literatura como uma linguagem artística com potencial emancipatório e o círculo de leitura literária como uma prática democrática, na qual pessoas dialogam, desconstroem preconceitos, problematizam, tecem suas relações com o mundo e se enxergam dentro de uma determinada cultura, enfatizamos mais uma vez a importância desta prática como promotora da cidadania, bem como o seu papel formativo.

Nosso percurso investigativo do Ler e Compartilhar endossa o papel precípuo da leitura literária, experiência que nos remete aos valores humanos por vezes tão esquecidos nas sociedades contemporâneas. Promove, assim, pelo viés da literatura, o resgate e a reflexão acerca das tradições e saberes da humanidade, tendo como base a construção solidária e autônoma de uma consciência crítica sobre o mundo que nos cerca.

\section{Referências}

Lajolo, Marisa (2000). A Leitura Literária na escola. São Paulo: Ática.

Lei $\mathrm{n}^{\circ} 10.639 / 2003$ se pode localizar em:

http://www.planalto.gov.br/ccivil_03/leis/2003/L10.63 9.htm

Leite, Sérgio A.S.; Oliveira, Lilian R (2004). Constituição do leitor: análise dos eventos de leitura no curso de pedagogia da Unicamp. Leitura: teoria $e$ prática. Campinas: ALB, SP: Global Editora, ano 22, n. 42, 19-31.

Ortiz, Renato (1994). Da raça à cultura: a mestiçagem e o nacional. São Paulo: Brasiliense.

Parreiras, Ninfa; Machado, Emília (2012). Da África e sobre a África: textos de lá e de cá. São Paulo: Cortez.

Souza, Maria Elena Viana (2009). Relações raciais no cotidiano escolar: diálogos com a Lei n.10.639/2003. Rio de Janeiro: Rovelle. 